\title{
INVESTIGACIÓN
}

Recibido: 29/03/2019 --- Aceptado: 29/06/2019 --- Publicado: 15/09/2020

\section{LA JUVENTUD MEXICANA FRENTE A UNA NUEVA TENDENCIA RECESIVA DE LA DEMOCRACIA}

\author{
Mexican youth are facing a new recessionary trend in democracy
}

José Luis Estrada Rodríguez¹: Benemérita Universidad Autónoma de Puebla. México

jluis.estrada@correo.buap.mx

Ketzalcóatl Pérez Pérez²: Benemérita Universidad Autónoma de Puebla. México ketzalcoatl.perez@correo.buap.mx

\section{RESUMEN}

El presente trabajo de investigación se centra en analizar la tendencia recesiva de la democracia en jóvenes mexicanos; se parte del supuesto que, cuando la actividad económica retrocede, se genera en la sociedad no solo una percepción de estancamiento económico sino democrático que se expresa en los niveles de abstinencia de las y los jóvenes a participar en la vida democrática de su país. El presente estudio busca determinar, mediante una muestra representativa de 400 jóvenes encuestados, correspondiente a 12 mil 884 electores de 18 a 23 años de la capital poblana, pertenecientes al distrito 12 electoral en México, si presentan una tendencia recesiva de su participación política. La relevancia de la investigación radica en que la Ciudad de Puebla, capital del Estado de Puebla ubicado en el centro de la República Mexicana, es una de las ciudades con mayor concentración de instituciones de educación superior -públicas y privadas- de México, para el año 2020, de acuerdo con la Secretaría de Educación Pública Federal, en Puebla operan 343 universidades, colocando a la entidad como la segunda a nivel nacional con más instituciones de este nivel educativo (SEP, 2020). Además de lo anterior, la entidad poblana recibe estudiantes de diferentes entidades federativas del país, de modo que es posible afirmar que los resultados que aquí se presentan, son representativos de

\footnotetext{
${ }^{1}$ Doctor en Ciencia Sociales por la Universidad Autónoma del Estado de México, posdoctorado en Ciencias Políticas y Sociales por la UNAM. Es profesor investigador de la Benemérita Universidad Autónoma de Puebla, en México y miembro del Sistema Nacional de Investigadores, nivel 1. Correo: jluis.estrada@correo.buap.mx http://orcid.org/0000-0003-0088-2157

2 Profesor Investigador Tiempo Completo de la Facultad de Ciencias de la Comunicación de la Benemérita Universidad Autónoma de Puebla. Doctorando en Educación Permanente. Maestro en Mercadotecnia. Licenciado en Ciencias de la Comunicación. Miembro del Cuerpo Académico de Comunicación Política. Orcid ID: orcid.org/0000-0002-5534-7234
} 
las conductas observables en las y los jóvenes mexicanos frente la democracia como forma de vida.

PALABRAS CLAVE: Democracia - participación - juventud y política.

\begin{abstract}
This research paper focuses on analyzing the recessionary trend of democracy in young Mexicans; it is assumed that, when economic activity recedes, not only a perception of economic but democratic stagnation is generated in society that is expressed in the levels of abstinence of young people to participate in the democratic life of their country. This study seeks to determine, through a representative sample of 400 young people surveyed, corresponding to 12 thousand 884 18-23-year-old voters from the population capital, belonging to the 12th electoral district in Mexico, whether they show a recessionary trend of their political participation. The relevance of the research is that the City of Puebla, capital of the State of Puebla located in the center of the Mexican Republic, is one of the cities with the highest concentration of higher education institutions - public and private - of Mexico, by 2020, according to the Federal Ministry of Public Education, in Puebla operate 343 universities, placing the entity as the second at the national level with more institutions of this level of education (SEP, 2020). In addition to the above, the poblana entity receives students from different federative entities of the country, so it is possible to affirm that the results presented here are representative of the observable behaviors in the Mexican youth versus democracy as a way of life.
\end{abstract}

KEY WORDS: Democracy - participation - youth and politics.

\title{
A JUVENTUDE MEXICANA LIDERANDO UMA NOVA TENDÊNCIA RECESSIVA DA DEMOCRACIA
}

\section{RESUMO}

O presente trabalho de pesquisa está focado em analisar a tendência recessiva da democracia em jovens mexicanos; se parte da suposição que, quando a atividade econômica declina, gera-se na sociedade não somente uma percepção de estagnação econômica mas também da democracia que se expressa nos níveis de abstinência dos jovens que participam na vida econômica do país. O presente estudo procura determinar, através de uma mostra representativa de 400 jovens entrevistados, correspondentes a 12 mil 884 eleitores entre 18 e 23 anos da capital de Puebla, pertencentes ao distrito 12 eleitoral no México, se apresentam uma tendência recessiva da sua participação política. A relevância da pesquisa é que a Cidade de Puebla, capital do Estado de Puebla localizado no centro da República Mexicana, é uma das cidades com maior concentração de instituições de educação superior públicas e privadas- do México, para o ano 2020, de acordo com a Secretaria de Educação Pública Federal, em Puebla operam 343 universidades, colocando a 
entidade como a segunda a nível nacional com mais instituições deste nível educativo (SEP, 2020). Além do anterior, a entidade de Puebla recebe estudantes de diferentes entidades federativas do país, de modo que é possível afirmar que os resultados que aqui se apresentam, são representativos das condutas observáveis nos jovens mexicanos diante da democracia como forma de vida.

PALAVRAS CHAVE: Democracia - participação - juventude e política.

\section{Como citar el artículo:}

Estrada Rodríguez, J. L. y Pérez Pérez, K. (2020). La juventud mexicana frente a una nueva tendencia recesiva de la democracia. [Mexican youth are facing a new recessionary trend in democracy].Vivat Academia. Revista de Comunicación, 152, 69-90. doi: $\quad$ http://doi.org/10.15178/va.2020.152.69-90 Recuperado de: http:// www.vivatacademia.net/index.php/vivat/article/view/1273

\section{INTRODUCCIÓN}

Cada país en el mundo posmoderno requiere de una economía sana para ser competitivo con sus similares, gracias al desarrollo educativo se pude mejorar la situación económica de cada nación. La participación activa de sus ciudadanos es fundamental para la construcción de un estado fuerte que refleje una economía sustentable.

En este punto la economía juega un papel fundamental para efectos de este estudio definiremos a la economía como "la ciencia que estudia las opciones a las que se enfrentan los seres humanos, individual o colectivamente e incluye las opciones políticas. Mientras más opciones tienen los individuos, más libertades tienen. De hecho, el conjunto de opciones de cada persona mide su libertad" Sanguinetty, J. (s.f)

La democracia inmersa en la vida de los ciudadanos que gozan de este tipo de gobierno, ayuda a las personas a alcanzar un nivel de bienestar mayor en comparación con los seres humanos que viven sin democracia así lo menciona Sanguinetty en su obra Interacción entre Democracia y Economía.

\section{OBJETIVOS}

El objetivo principal es identificar la relación existente entre un clima económico deprimido o en franca recesión, y la recesión de la democracia como un fenómeno socio-político que afecta a la juventud que cursa estudios de tipo superior en México; lo anterior, con el propósito de analizar y diagnosticar la viabilidad democrática del país a partir de las percepciones políticas de su juventud.

\section{METODOLOGÍA DE INVESTIGACIÓN}


Se realizó una investigación exploratoria con carácter transversal llevada a cabo mediante la recolección de información primaria a través de una encuesta aplicada a 400 jóvenes, con edad de 18 a 23 años. Se eligió esta edad porque los jóvenes van en un proceso de transición de la etapa adolescente a la etapa adulta, lo cual configura un espacio de interés porque ahí se forman las preferencias políticas e ideológicas de acuerdo a varios autores. Estos jóvenes se eligieron en el distrito 12 que conforman las siguientes colonias: el Centro Histórico (cuadrante sur-oriente), El Carmen, El Cerrito, Bugambilias, Granjas del Sur, Arboledas de Loma Bella, Unidad Habitacional San Jorge, San José el Aguacate, Santa María Guadalupe Tecola, San José El Rincón, Barrio de la Luz, La Providencia, Lomas de Chapultepec, Lomas del Mármol, Toltepec Álamos, Barrio de San Miguel, Barrio de Santa Catarina, Quetzalcóatl, El Oasis Valsequillo, así como 281 mil 762 ciudadanos que cuentan con credencial de elector vigente.

Para el desarrollo del instrumento aplicado a los jóvenes, se consideró las siguientes variables de análisis: a) Participación Política, b) Democracia y, c) Tendencia Recesiva. Este último rubro se refiere cuando la actividad económica retrocede y genera en la sociedad no solo una percepción de estancamiento económico sino democrático por la abstinencia de los grupos sociales a participar en la vida democrática de su país.

La presente investigación está enfocada en estudiar la participación ciudadana en la vida política de México. Esta investigación es de tipo cualitativo se pretende analizar las opiniones y críticas sobre la política, en los jóvenes en un rango de edad entre los 18 a 23 años que radican en la capital poblana dentro del Distrito 12.

En el caso de ésta investigación se pretende analizar las variables y la relación entre las mismas, sin intervenir en la participación hombres y mujeres en un rango de edad entre los 18 a 23 años que radican en la capital poblana vivan dentro del Distrito 12, se eligió esta muestra por considerar que los sujetos de investigación tienen las características apropiadas para este análisis, toda vez que el centro de la ciudad de Puebla, provee de valores culturales y educativos por encima de otros distritos electorales o municipios.

De igual forma, es preciso señalar que esta investigación se inclina al tipo retrospectivo ya que la participación ciudadana en la política es un tema que ha sido objeto de estudio al igual que su impacto en la sociedad y lo que se busca es determinar si influye una tendencia recesiva por una percepción de estancamiento económico de hombres y mujeres en un rango de edad entre los 18 a 23 años que radican en la capital poblana perteneciente a un espacio territorial determinado.

Al aplicar la encuesta, se consideró un espacio y tiempo determinado para el análisis que toma una fotografía del evento, por lo cual no pretende dar continuidad a este proceso de influencia. Asimismo, se consideró en el instrumento de aplicación una investigación transversal que sólo se aplicaría durante un periodo determinado, 
antes de las elecciones a gobernador 2019 en el estado de Puebla y sin posibilidad de obtener continuidad los resultados obtenidos.

El cuestionario se aplicó en forma de entrevista individual, mediante una visita espacios abiertos; donde se eligió a los jóvenes que cumplieran con las características específicas del estudio (18 a 23 años). Se eligió para la muestra de este estudio, hombres y mujeres entre 18 a 23 años de edad que actualmente habitan dentro del Distrito 12 en el estado de Puebla de un universo de 12 mil 884 que forman parte de la lista nominal, ante el Instituto Nacional Electoral. El tamaño de la muestra por tanto fue de 400 encuestados, con un margen de 5 por ciento de error y 95 por ciento de confiabilidad, una vez que se descartaron aquellas encuestas con error en la captura, siguiendo la fórmula de Yamane (1967):

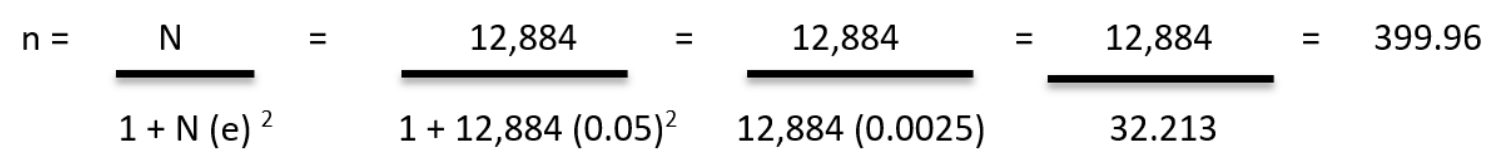

Figura 1. Tamaño de muestra

Fuente: Yamane (1967) Statistics: an introductory analysis, New York: Harper and Row, USA.

El levantamiento de la información se realizó mediante un grupo de 10 encuestadores que aplicaron el instrumento de manera física, el lunes 11 de febrero de 2019 en un horario de 9 a 15 horas, en el espacio físico que corresponde a este distrito electoral; y se obtuvo información relevante como a continuación se describe en el siguiente apartado.

Con respecto al procesamiento de datos, se realizó mediante el paquete estadístico: SPSS 23 de IBM, posteriormente los datos fueron exportados al programa de EXCEL 2013, como una hoja de cálculo para su interpretación y análisis.

\section{RESULTADOS}

Para tener un panorama mejor del tema es importante concebir la importancia y relación que guarda la democracia, el desarrollo económico y la tendencia recesiva de la democracia en jóvenes mexicanos; cuando la actividad económica retrocede y genera en la sociedad no solo una percepción de estancamiento económico sino democrático por la abstinencia de los grupos sociales a participar en la vida democrática de su país.

En nuestro país uno de los problemas que la población señala con mayor incidencia es la economía como lo muestra la siguiente gráfica: 

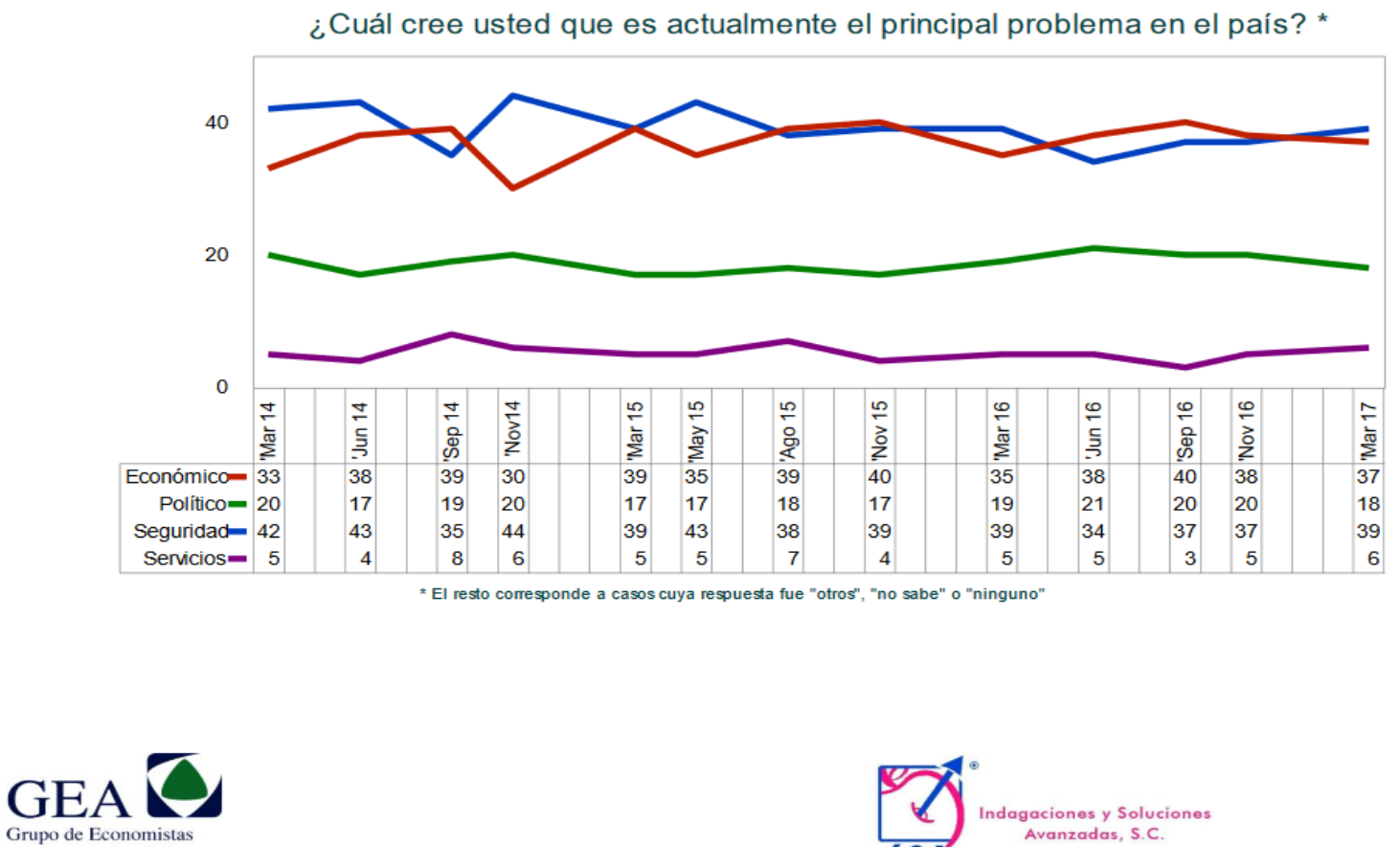

y Asociados

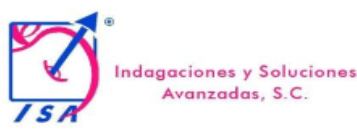

Gráfico 1. ¿Cuál cree usted que es actualmente el principal problema del país? Fuente: Primera Encuesta Nacional de Opinión Ciudadana 2017.

En la gráfica muestra claramente la percepción negativa sobre la economía de México, no es de extrañarse que la tendencia recesiva de la democracia en jóvenes mexicanos aumente.

Para efectos de este estudio retomamos el concepto de democracia como "una forma organizada de la libertad, tanto en sus aspectos políticos como económicos. De hecho, si no existen suficientes libertades políticas, como poder elegir a los gobernantes, las libertades económicas que puedan existir serán precarias" Sanguinetty, J. (s.f).

Las condiciones económicas de Latinoamérica predominantes en un momento dado y que determinan en mayor o menor rango de las oportunidades de empleo, ingreso e inversión en la sociedad Mexicana, significa que a medida que una economía no es sana su población la relaciona con un mal manejo de las políticas públicas-económicas y esta situación se ve reflejada en un rechazo a la participación política y un repudio al sistema político.

Significa que los ciudadanos sean libres de emplearse donde lo deseen de acuerdo a sus calificaciones, no pueden hacerlo fácilmente por la falta de empleos disponibles. Lo mismo se puede aplicar cuando a pesar de que existen amplias libertades de inversión o de generar ingresos, no aparecen las oportunidades debido a la coyuntura económica del país. Sanguinetty, J. (s.f). 
Para el $48 \%$ de las familias latinoamericanas el problema más importante es la economía como lo señala el informe de Latinobarómetro 2018.

El ingreso, la estabilidad del trabajo, la seguridad social, la violencia, el temor a ser víctima, pasan a ser los temas centrales que aquejan a los ciudadanos de América Latina.
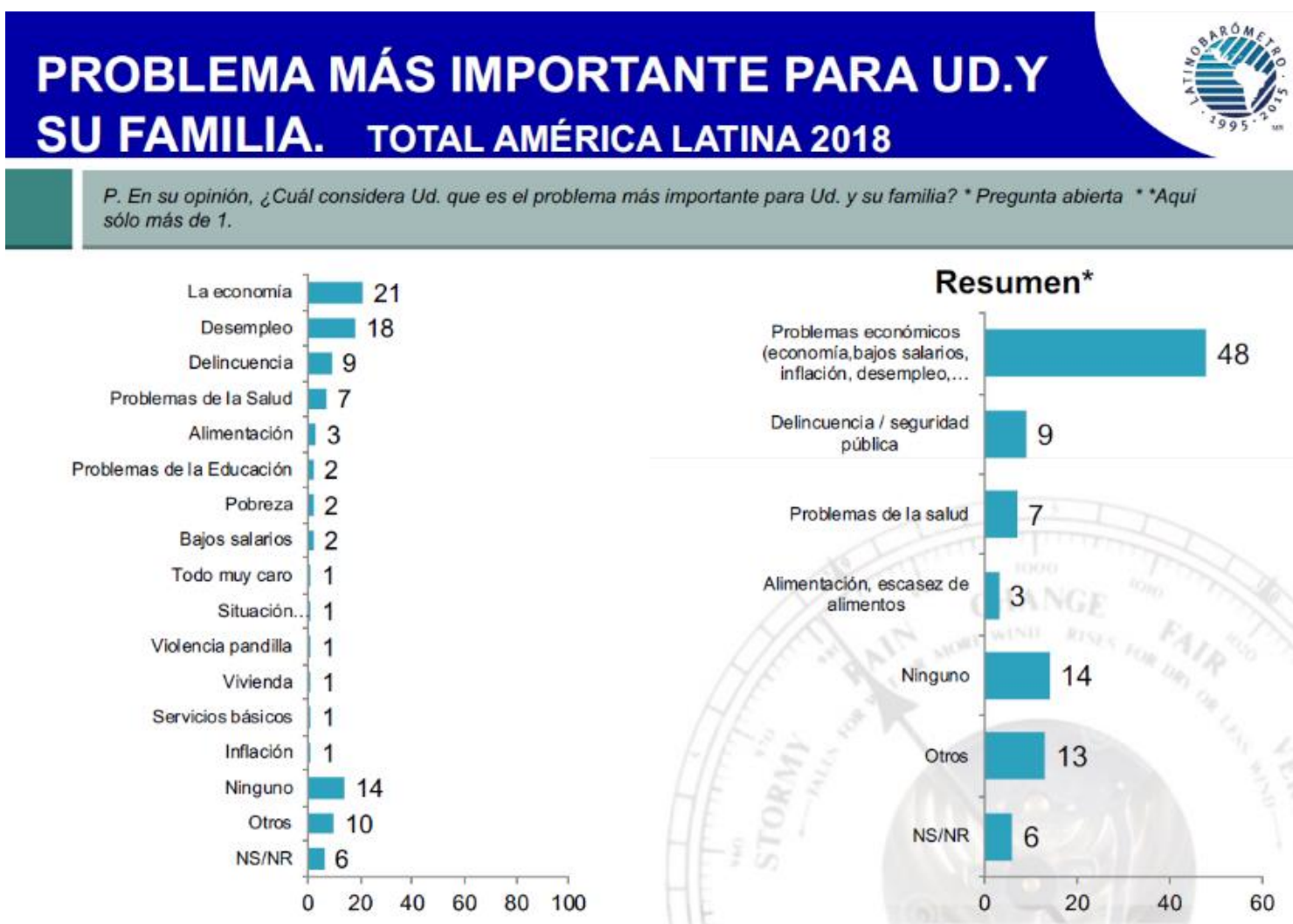

Gráfico 2. Problemas más importantes para usted y su familia

Fuente: Latinobarómetro 2018.

El último reporte de Latinobarómetro en el 2018 señala que son diez países de la región donde $10 \%$ o menos de su población declaran que hay buena situación económica. Entre ellos se ubican Colombia, México, Costa Rica, Brasil y Venezuela, todos países que tuvieron elecciones presidenciales en 2018. La única excepción en ese aspecto es Paraguay que tuvo elecciones presidenciales y un $15 \%$ de la población declara que hay buena situación económica, estando entre los cinco países de la región que declaran tener mejor situación económica.

Otra arista, relacionada con el tema de este estudio, es la participación política de los jóvenes en el marco de la democracia politizada en América Latina, este es un fenómeno que merece ser estudiado a profundidad, en el marco de algunos rasgos característicos del sistema político mexicano: el presidencialismo, la legitimidad del Estado, de sus congresos, gobiernos, y de las instituciones de la democracia. 


\subsection{Participación Política de los Jóvenes Mexicanos en la Construcción de la Democracia.}

“Claramente la democracia es un resultado de alguna forma de acción colectiva. En estos términos podemos afirmar que la democracia es posible si existen los incentivos suficientes para organizarla o mantenerla" Sanguinetty, J. (s.f).

Los ciudadanos en América Latina juegan un papel hegemónico en la toma de decisiones de cada Nación. Ya sea a través de su voto electoral o su abstencionismo. Los dos son actos sin duda de un mensaje claro, de acuerdo, desacuerdo o indiferencia Pérez, K. Mendieta, A. Coutiño, F. (2018).

(...) cabe entender a la ciudadanía como una conjunción de tres elementos constitutivos: la posesión de ciertos derechos, así como la obligación de cumplir ciertos deberes en una sociedad específica; pertenencia a una comunidad política determinada (normalmente el Estado), que se ha vinculado generalmente a la nacionalidad; y la oportunidad de contribuir a la vida pública de esa comunidad a través de la participación... García y Lukes (1999).

En el ejercicio de la democracia es importante considerar la actuación del Estado, la Ciudadanía y las Instituciones. Todo esto en el marco legal escrito en la Constitución Política de los Estados Unidos Mexicanos.

Para efectos de este estudio hablaremos de la ciudadanía mexicana de los jóvenes ubicados en el grupo etario de los 18 a los 23 años, considerando este rango para la iniciación a la vida política y democrática de México y para conocer a través de la muestra, si su percepción de la política actual tiene o no relación con una tendencia recesiva de la democracia; cuando la actividad económica retrocede y genera en la sociedad no solo una percepción de estancamiento económico sino democrático produciendo la abstinencia de los grupos sociales, y en este caso de la población joven de México, de participar en la vida democrática de su país.

La participación de la ciudadanía es fundamental en la construcción del Estado, no podemos establecer una sociedad democrática sin la participación de su sociedad.

Las bases de cualquier democracia sólida se encuentran en la participación ciudadana en la vida política que constituye a una Nación. Como lo muestra la siguiente gráfica los jóvenes entre los 18 y los 23 años son el grupo predominante de la población mexicana, de ahí su relevancia política al punto que desde principios del siglo XXI se hablaba de que México contaba con un bono democrático.

Vivat Academia. Revista de Comunicación. 15 septiembre / 15 diciembre 2020, nº 152, 69-90 


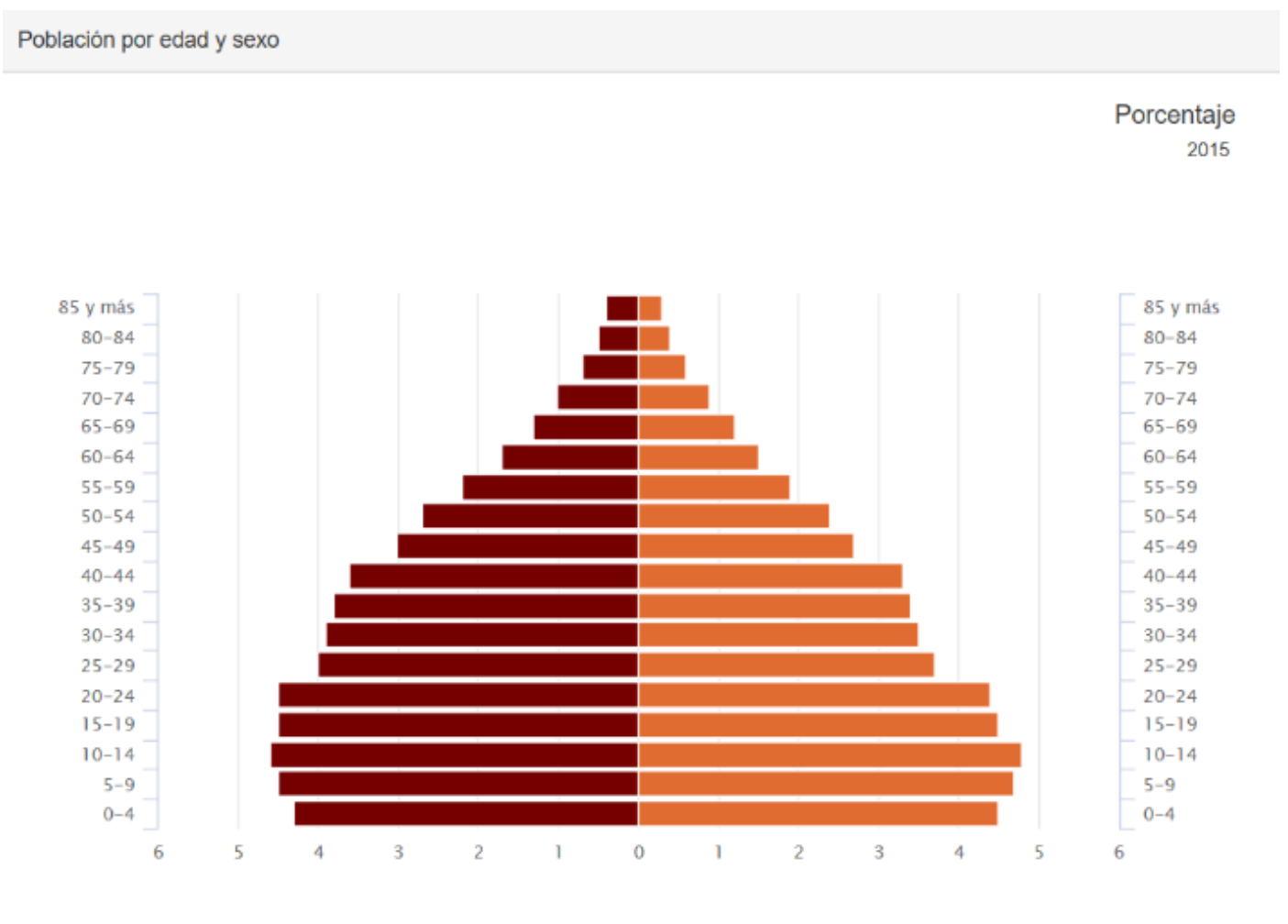

Gráfico 3. Población por edad y sexo

Fuente: INEGI 2015.

La importancia de educar a las generaciones jóvenes en los quehaceres de la política es fundamental. Como lo señala Horbath y Gracia (2013) “Asimismo, el relevo generacional de la población permite educar a las sociedades futuras para consolidar procesos democratizantes".

Los jóvenes mexicanos conciben a la democracia como los derechos y obligaciones que tienen como ciudadanos sin tener en claro cuales derechos y cuales obligaciones.

La democracia se asienta en cuatro ideas principales para O'Donnell, Lazetta y Vargas, (2003): a) el ser humano como sujeto portador de derechos; b) la sociedad organizada de modo que garantice el ejercicio y promueva la expansión de la ciudadanía; c) las elecciones libres y competitivas, junto con la vigencia del Estado de derecho, como condición necesaria, aunque no suficiente, de la democracia, y d) la especificidad histórica de los pueblos latinoamericanos en sus procesos de construcción nacional.

Para Cuna (2012) “los jóvenes enfrentan un escenario desalentador, en el mapa nacional siguen siendo los más afectados no solo por el desempleo, sino también por la falta de cobertura sanitaria, la discriminación, la violencia y la lucha contra el crimen organizado". 
Otro punto fundamental en la construcción de la democracia es la educación, si bien no es un punto principal de este estudio es indispensable referirnos a ella porque gracias a esta se transmite no solo conceptos sino la praxis de la vida democrática.

"La necesidad de fortalecer la organización y la participación social viene sien do históricamente destacada en el campo de la educación, particularmente desde el pensamiento y las fuerzas progresistas" Torres, R. (2001). “La participación social en la educación apareció en escena formalmente en México a partir de la reforma educativa de 1993, al quedar asentados en la Ley General de Educación (LGE) la creación de diferentes órganos de participación social.

En México los jóvenes entre 18 a los 23 años mantienen una participación limitada en la vida política pero cabe señalar que cada participación debe sustentarse en la enseñanza misma que no está claro en el sistema educativo actual en qué materias o asignaturas se retoma desde los niveles educativos básicos hasta de educación superior.

\subsection{Vida democrática de los jóvenes}

De la encuesta aplicada a 400 jóvenes entre los 18 a los 23 años se obtuvieron los siguientes resultados:

\section{JÓVENES ENCUESTADOS 400}

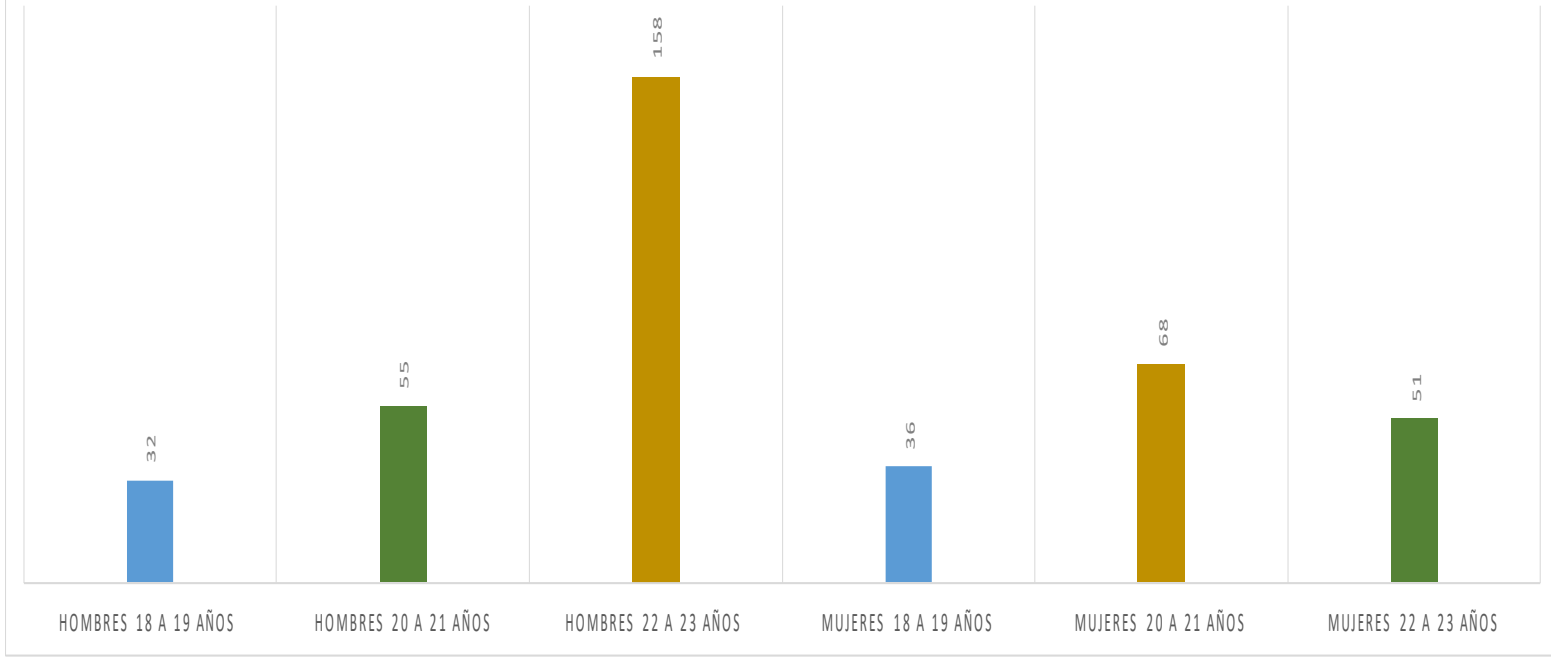

Gráfico 4. Jóvenes Encuestados.

Fuente: Elaboración propia.

De 400 encuestados 158 fueron hombres de 22 a los 23 años en comparación a 68 mujeres en el mismo rango de edad. 55 fueron hombres de 20 a 21 años de edad en 
comparación con 51 mujeres en el mismo rango de edad y finalmente 36 fueron mujeres de 18 a 19 años de edad en comparación a 32 hombres en el mismo rango de edad.

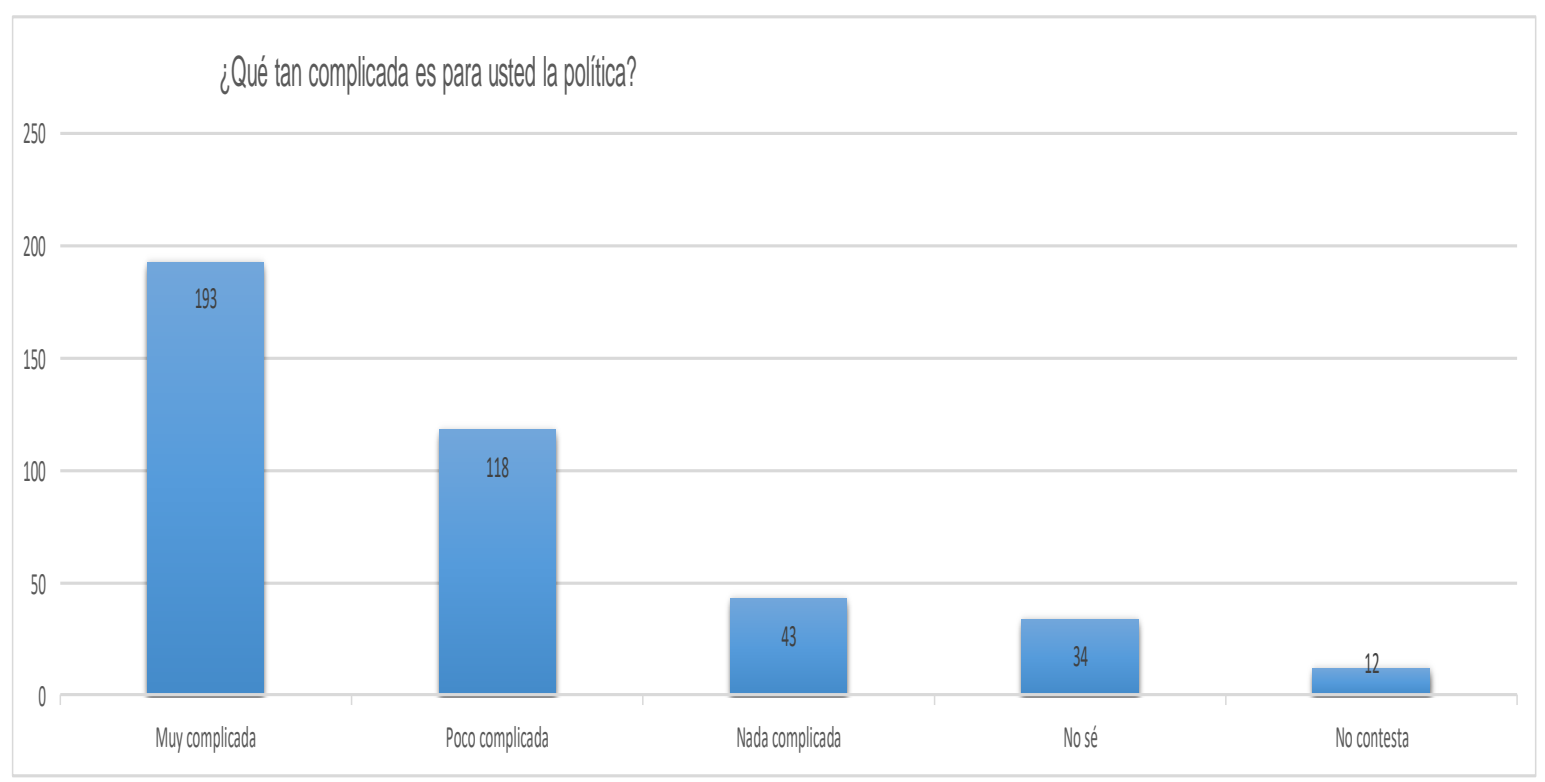

Gráfico 5. ¿Qué tan complicada es para usted la política?

Fuente: Elaboración propia.

El estudio encontró una tendencia marca por los jóvenes que piensan que la política es complicada con el $48.25 \%$. El $29.50 \%$ consideran a la política poco complicada. El $10.75 \%$ contestaron nada complicada, $8.5 \%$ no saben si lo es y por último el $3 \%$ no contesto. 
Estrada Rodríguez, J. L. y Pérez Pérez, K.

La juventud mexicana frente a una nueva tendencia recesiva de la democracia

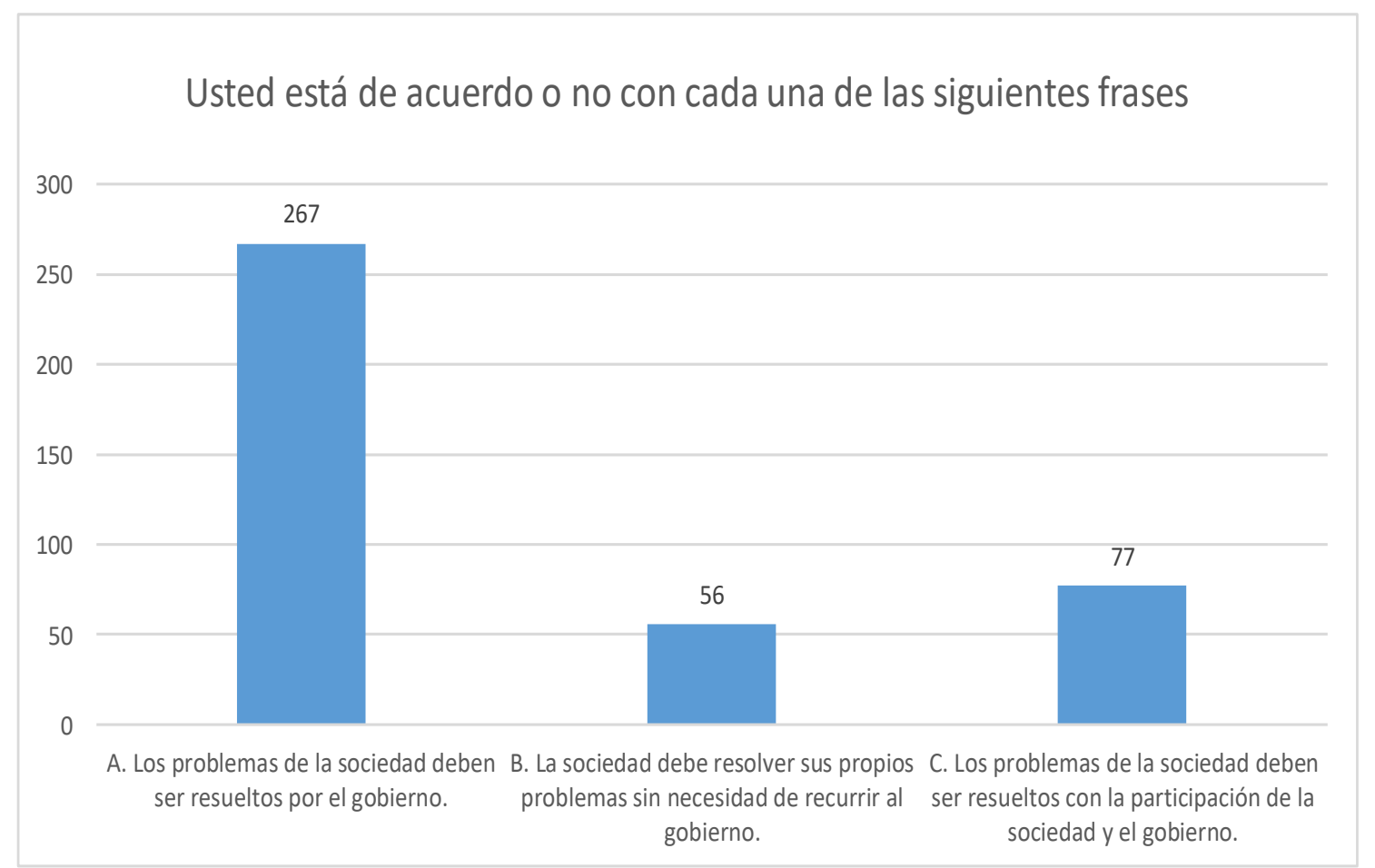

Gráfico 6. Usted está de acuerdo o no con cada una de las siguientes frases.

Fuente: Elaboración propia.

Para el $66.75 \%$ de los jóvenes encuestados los problemas de la sociedad deben ser resueltos por el gobierno. $14 \%$ piensa que la sociedad debe resolver sus propios problemas sin necesidad de recurrir al gobierno. Por último, el 19.25\% afirma que los problemas deben ser resueltos con la participación de la sociedad y el gobierno.

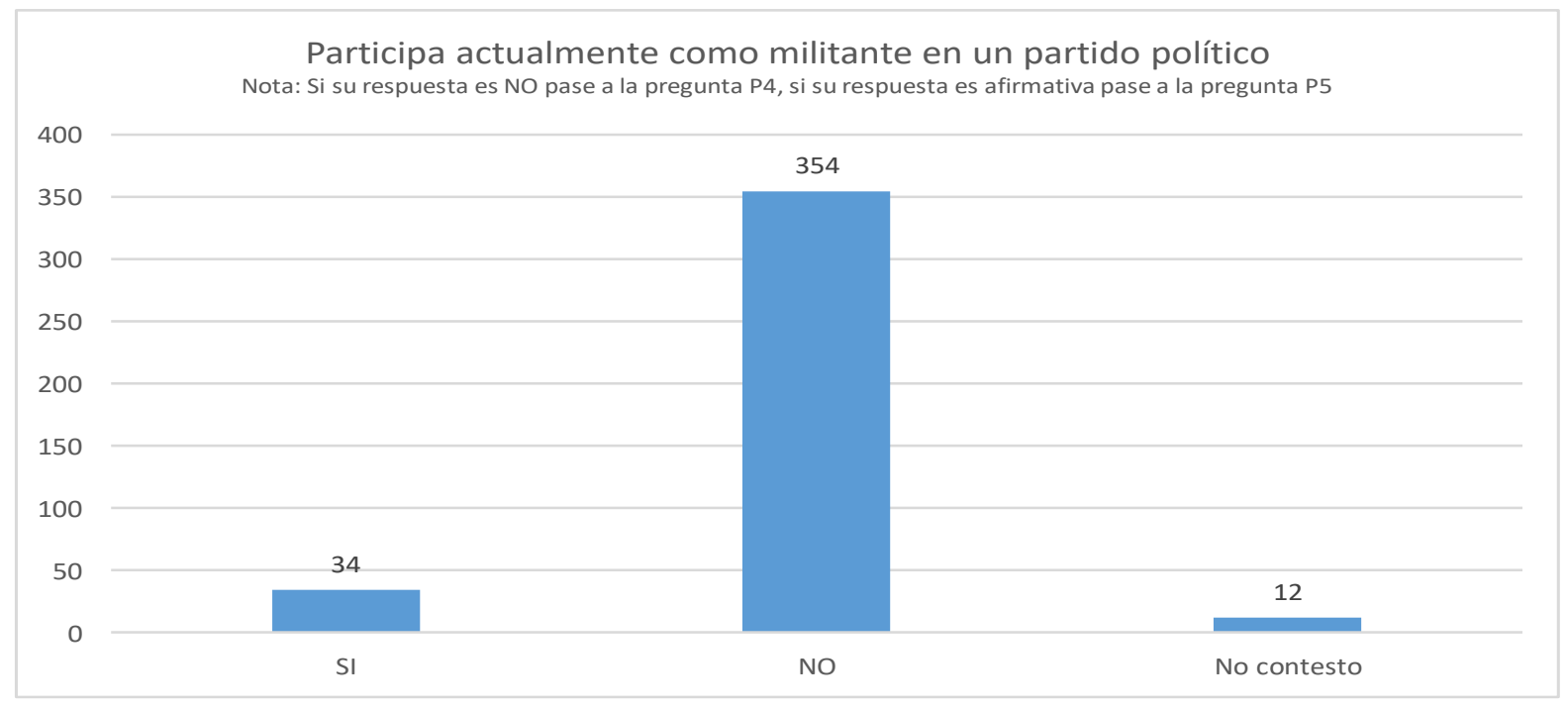

Gráfico 7. Participa actualmente como militante en un partido político.

Fuente: Elaboración propia. 
La investigación arrojó que el $88.50 \%$ de los encuestados no participan como militante en un partido político. El $8.5 \%$ si milita y el 3\% no contesto a la pregunta.

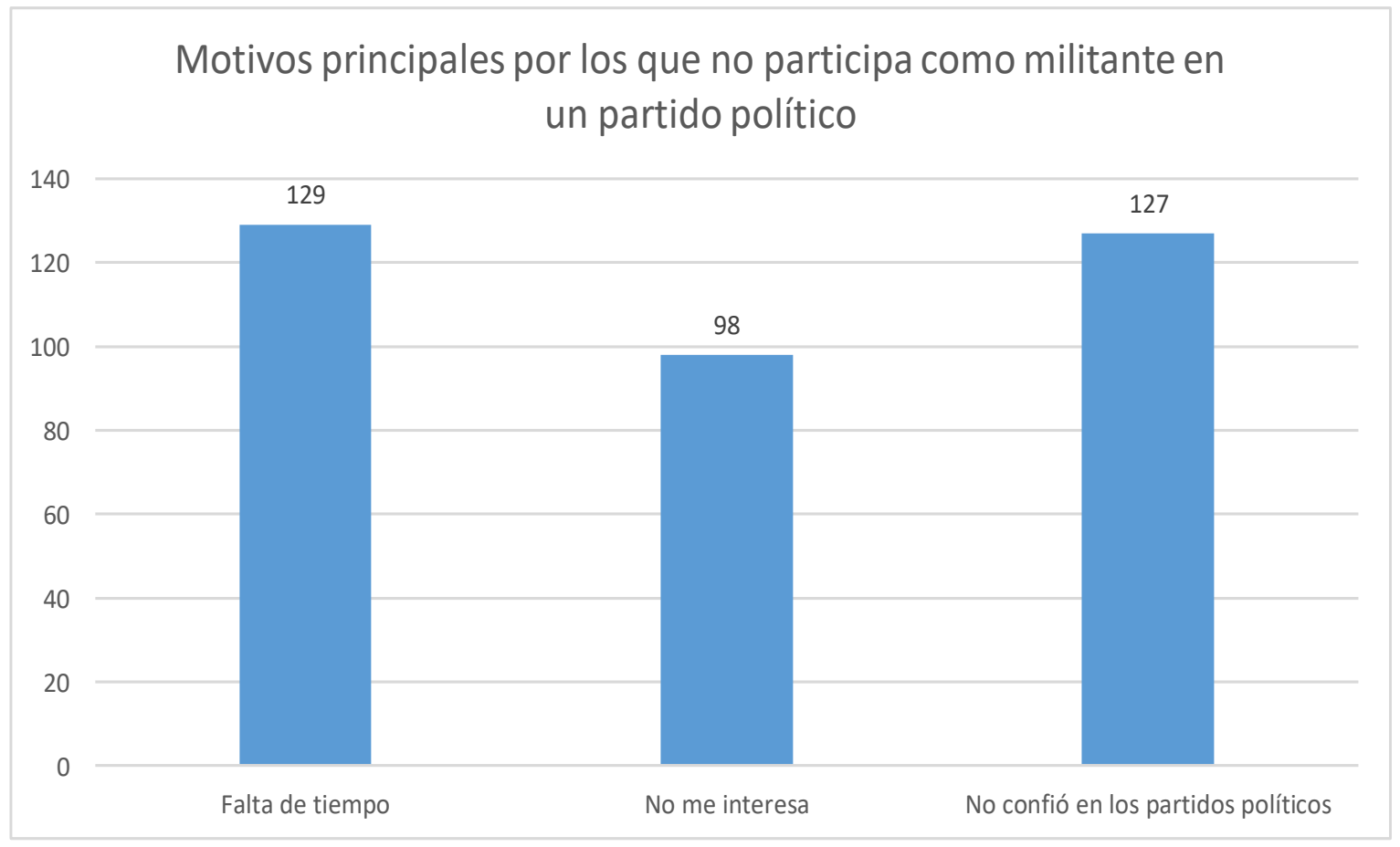

Gráfico 8. Motivos principales por los que no participa como militante en un partido político.

Fuente: Elaboración propia.

De los 366 encuestados que no participan como militantes en un partido político respondieron los motivos. El $35.25 \%$ afirma que no tiene tiempo para militar dentro de un partido político. El $26.78 \%$ no le interesa y el $34.70 \%$ afirma que no confía en los partidos políticos. 
Estrada Rodríguez, J. L. y Pérez Pérez, K.

La juventud mexicana frente a una nueva tendencia recesiva de la democracia

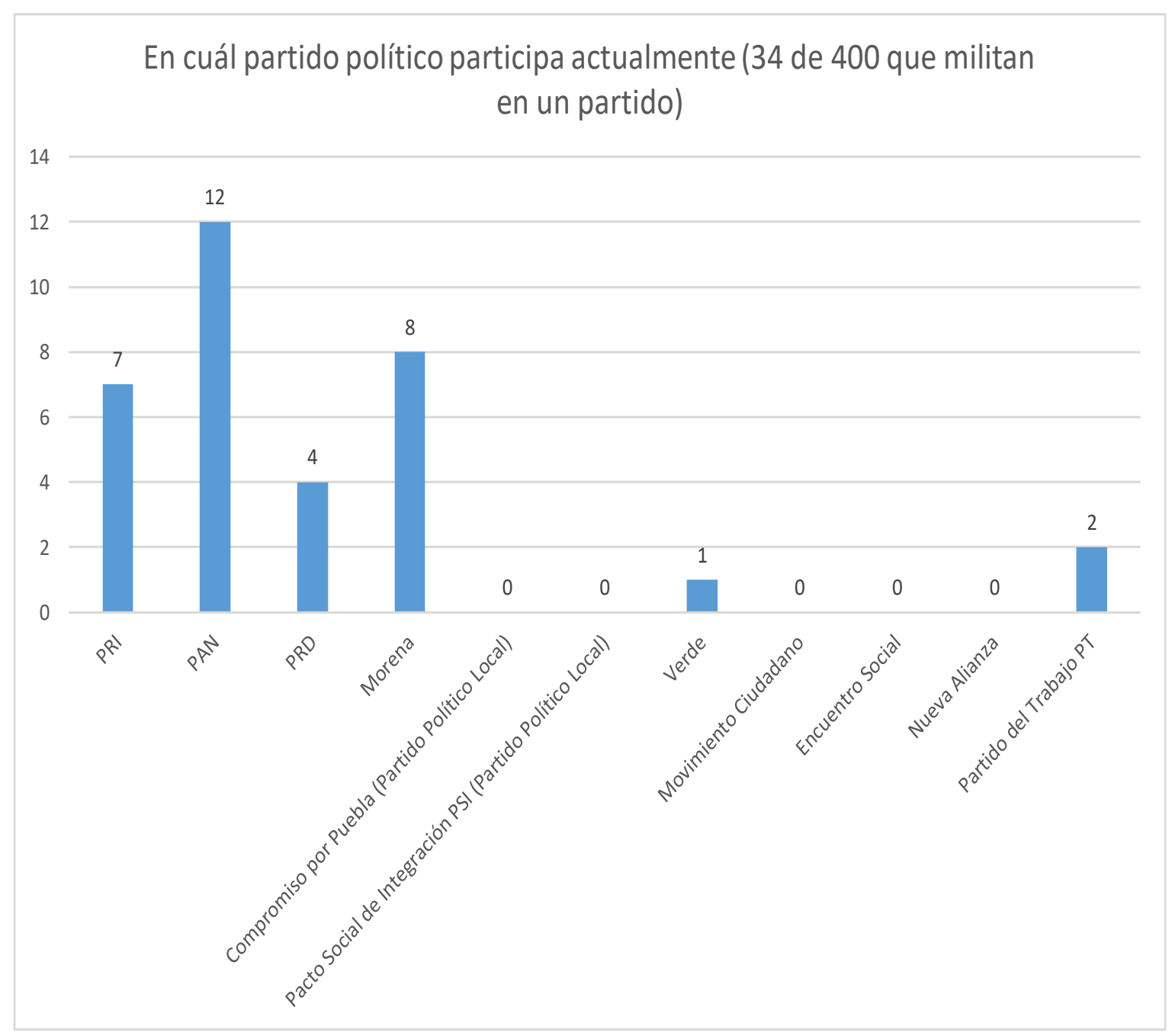

Gráfico 9. En cuál partido político participa actualmente.

Fuente: Elaboración propia.

El estudio encontró un desinterés por militar dentro de un partido político solo 34 jóvenes de 400 encuetados afirmaron pertenecer a un partido. 7 militan en el PRI, 12 en el PAN, 8 en MORENA, 2 en el Partido del Trabajo y 1 en el Partido Verde. 
Estrada Rodríguez, J. L. y Pérez Pérez, K.

La juventud mexicana frente a una nueva tendencia recesiva de la democracia

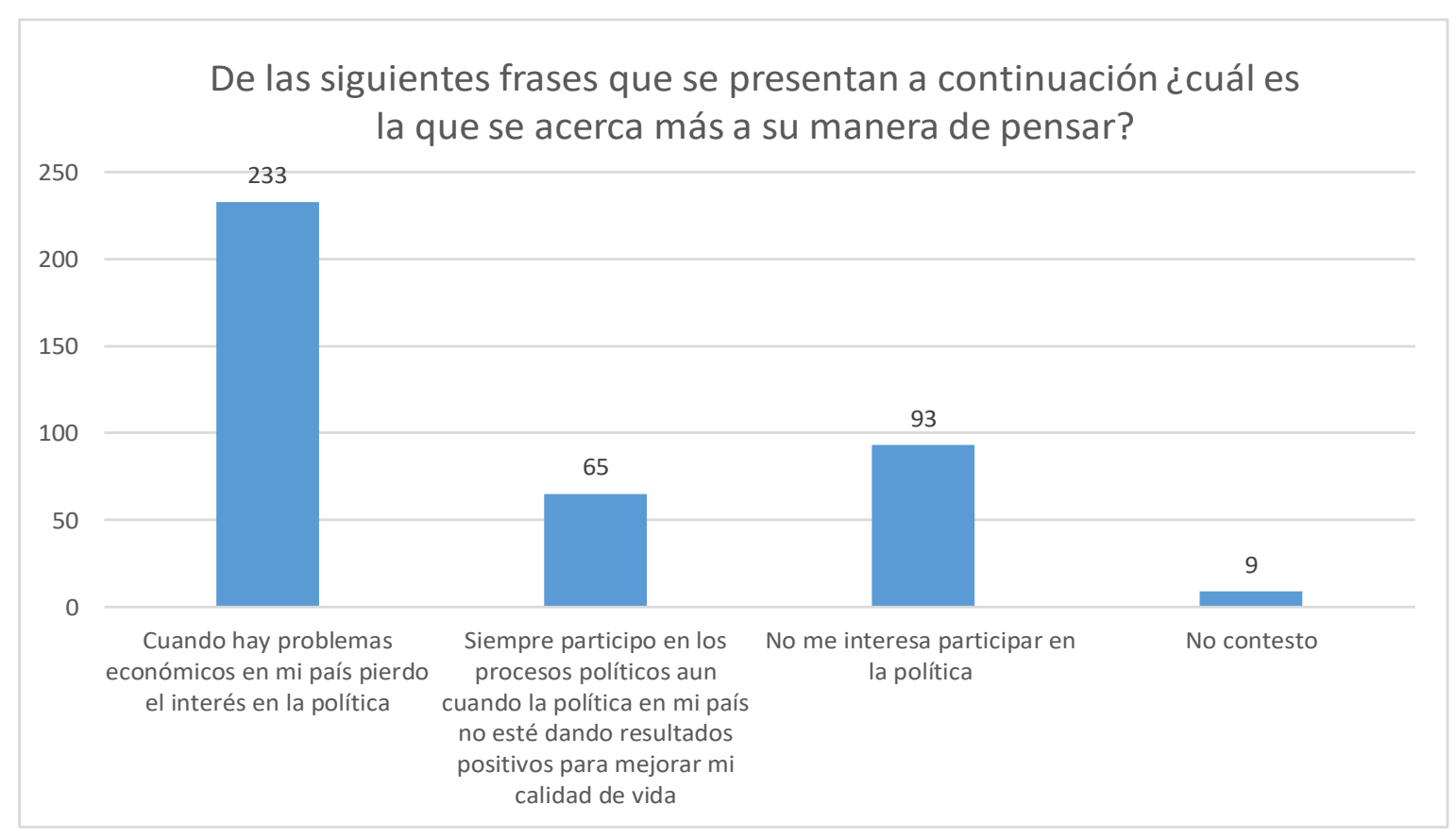

Gráfico 10. ¿Cuál es la que se acerca más a su manera de pensar?

Fuente: Elaboración propia.

El estudio encontró que un $30.50 \%$ de los encuestados afirma que la democracia es una forma de gobierno en la que el poder político es ejercido por los ciudadanos. $20.50 \%$ piensan que la participación es importante en un sistema democrático; $8 \%$ afirman que, en algunas circunstancias, un gobierno autoritario puede ser preferible a uno democrático; $3 \%$ encuestados creen que no es necesario la participación en un sistema democrático; $38 \%$ piensan que actualmente no se cumple con el concepto de democracia en México.

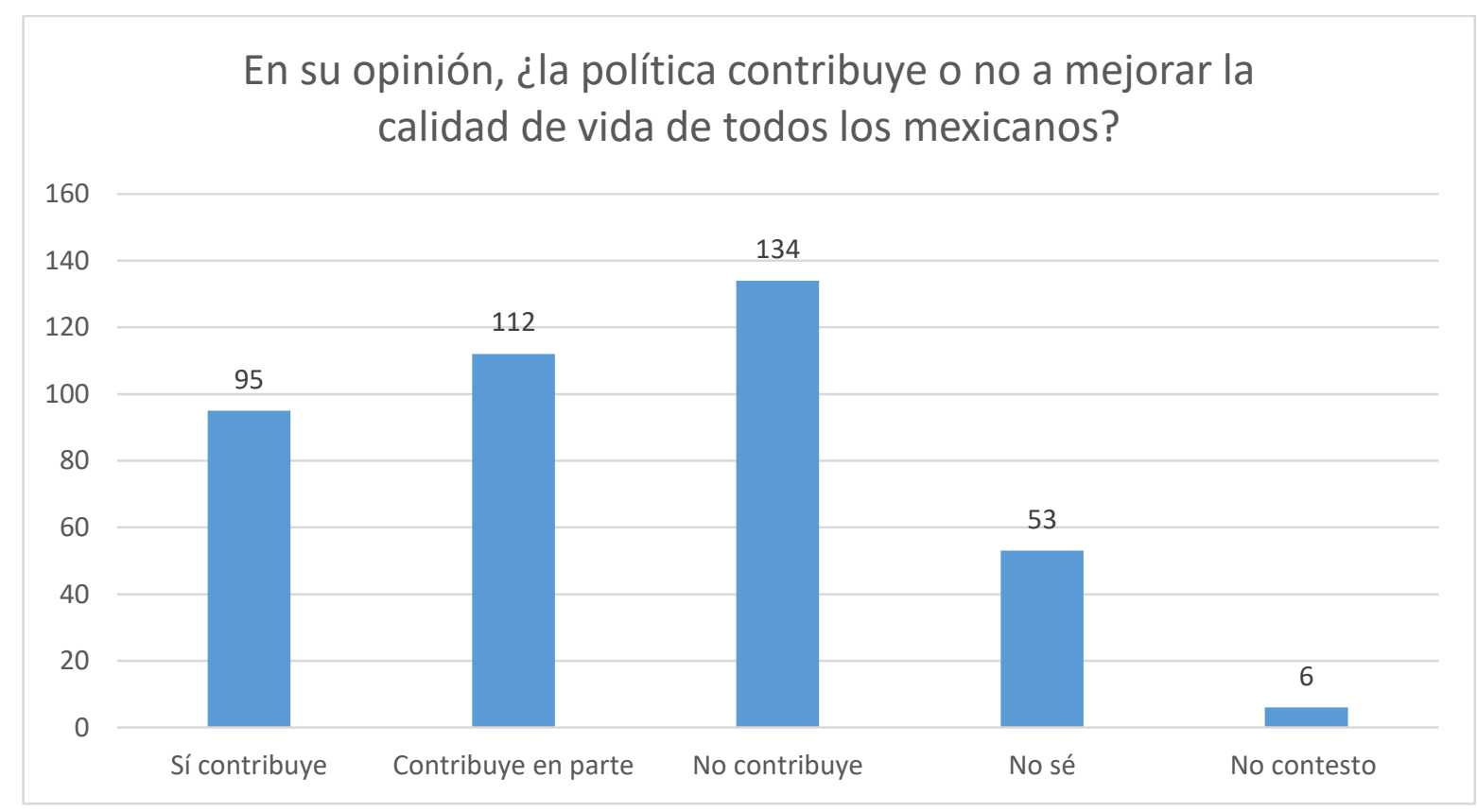

Vivat Academia. Revista de Comunicación. 15 septiembre / 15 diciembre 2020, nº 152, 69-90 
Gráfico 11. ¿Cuál es la que se acerca más a su manera de pensar?

Fuente: Elaboración propia

El 58.25\% piensan que cuando hay problemas en la economía de México pierden el interés en la política. $16.25 \%$ afirman que siempre participan en los procesos políticos aun cuando la política en México no esté dando resultados positivos para mejorar su calidad de vida. $23.25 \%$ no les interesa participar en la política mexicana y el $2.25 \%$ no contestaron.

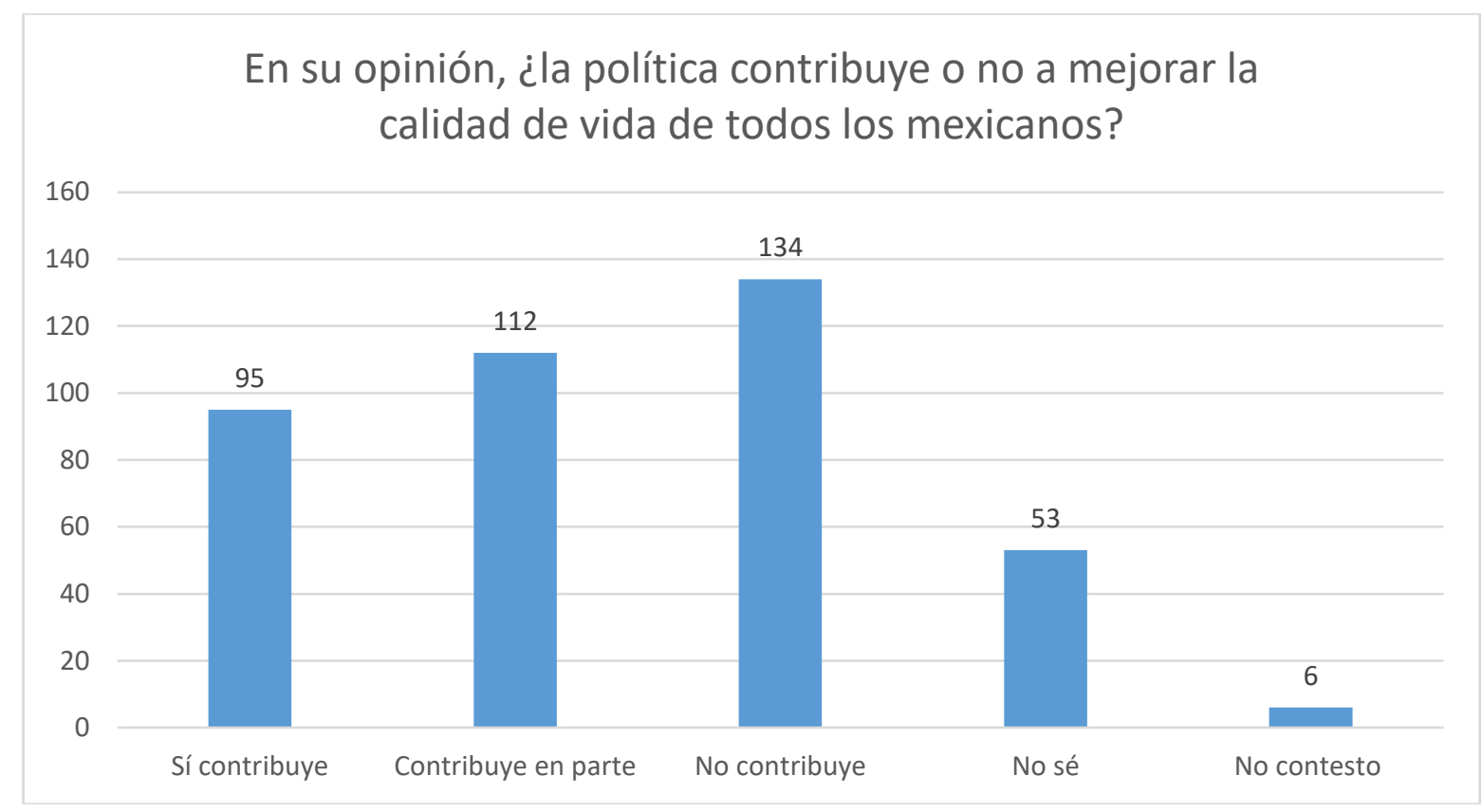

Gráfico 12. ¿La política contribuye o no a mejorar la calidad de vida de todos los mexicanos?

Fuente: Elaboración propia.

El $23.75 \%$ de los encuestados afirman que la política contribuye a mejorar su calidad de vida. $28 \%$ respondieron que en parte contribuye. $33.50 \%$ piensan que no contribuye la política de México a su calidad de vida. El 13.25\% no lo sabe y el 1.5\% no contestó. 
Estrada Rodríguez, J. L. y Pérez Pérez, K.

La juventud mexicana frente a una nueva tendencia recesiva de la democracia

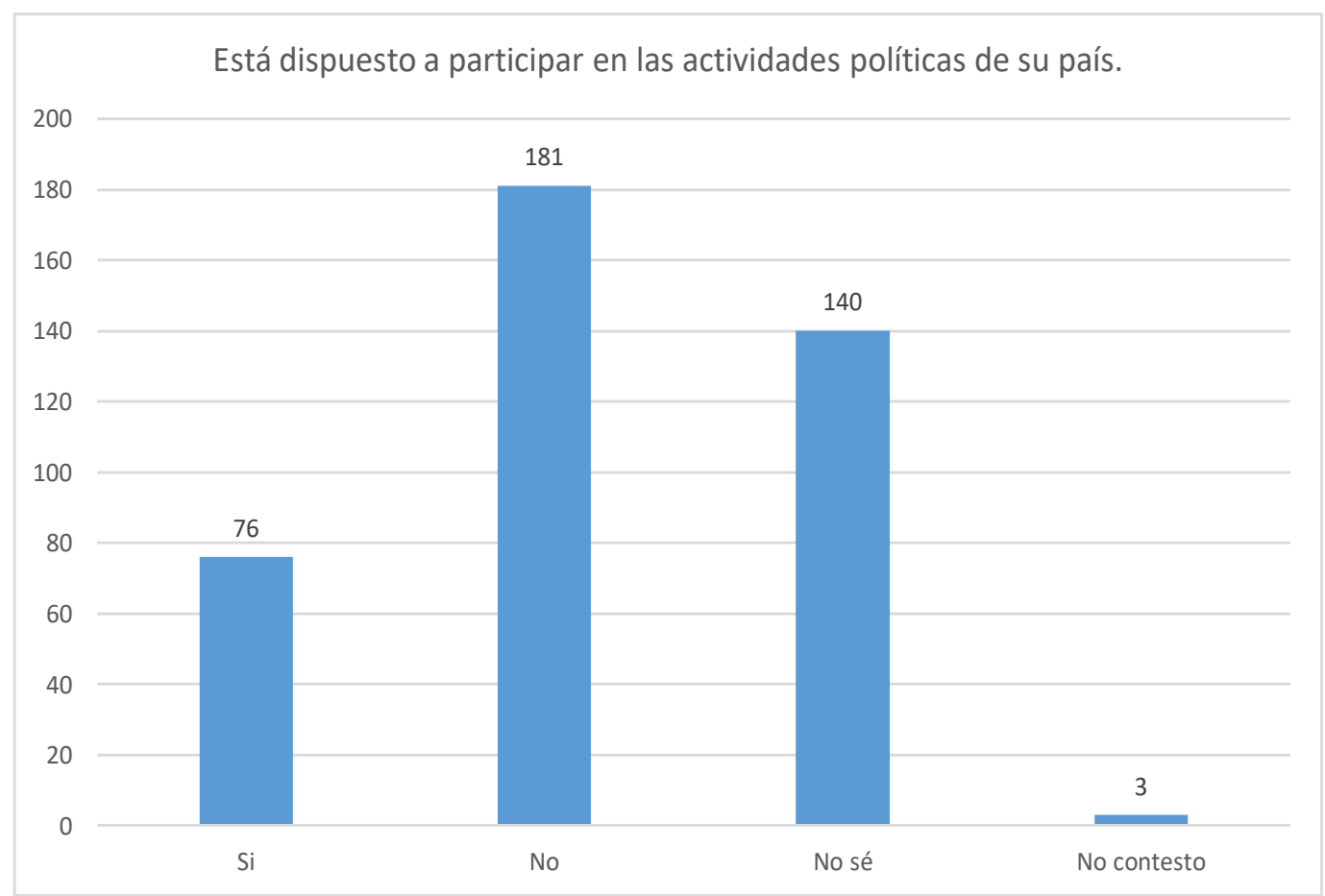

Gráfico 13. Está dispuesto a participar en las actividades políticas de su país.

Fuente: Elaboración propia.

El 19\% de los encuestados están dispuestos a participar en actividades políticas en México. $45.25 \%$ de los encuestados no están dispuestos a participar en actividades políticas. $35 \%$ no lo sabe si participará y sólo el $0.75 \%$ no contestaron.

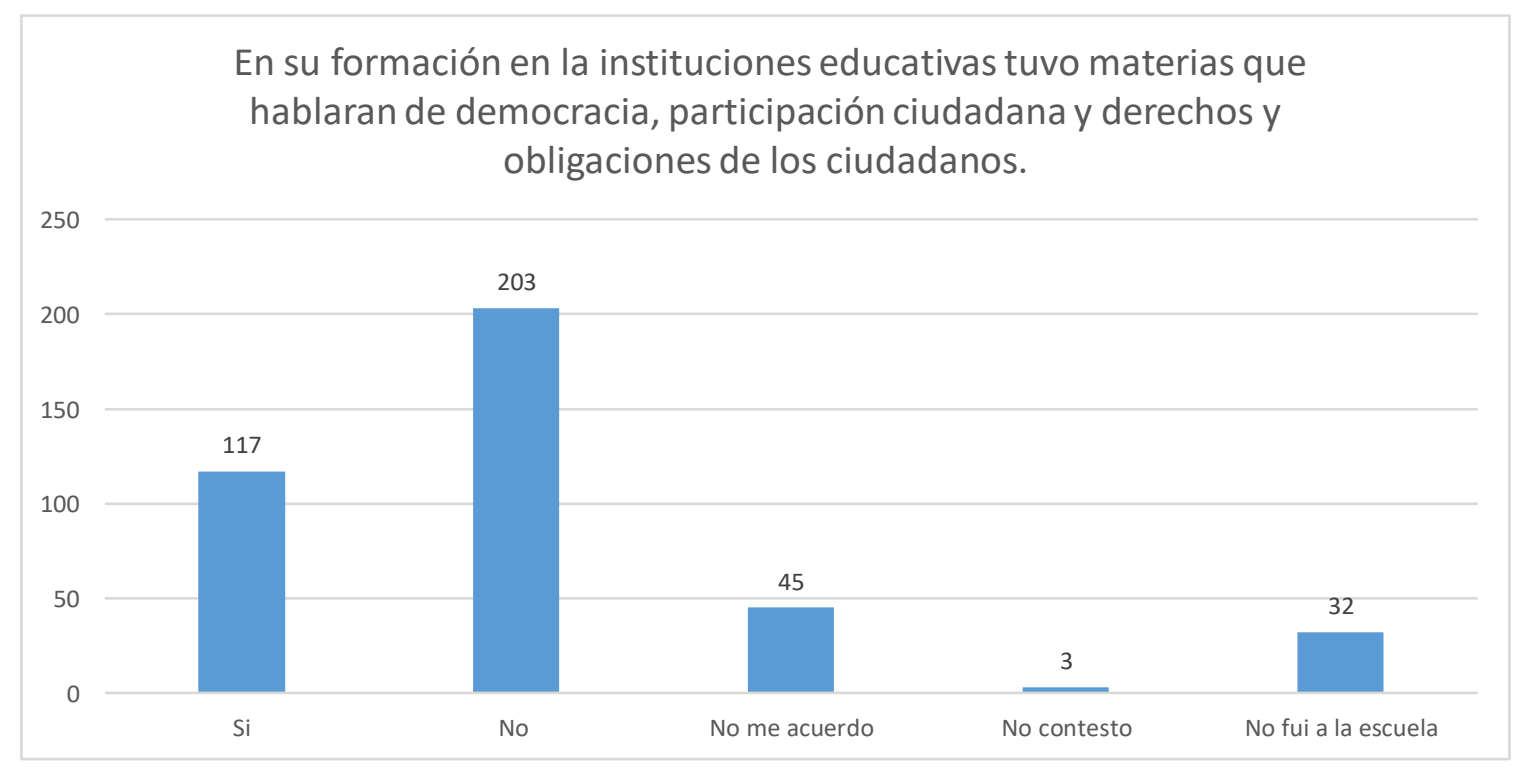

Gráfico 14. En su formación en las instituciones educativas tuvo materias que hablaran de democracia, participación ciudadana y derechos y obligaciones de los ciudadanos

Vivat Academia. Revista de Comunicación. 15 septiembre / 15 diciembre 2020, n 152, 69-90 


\section{Estrada Rodríguez, J. L. y Pérez Pérez, K. \\ La juventud mexicana frente a una nueva tendencia recesiva de la democracia}

\section{Fuente: Elaboración propia}

El 29.25\% afirman que, dentro de su formación educativa, tuvieron una materia donde abordaron temas de democracia, participación ciudadana y derechos y obligaciones de los ciudadanos; $50.75 \%$ no recibieron materias dentro del sistema educativo que abordaran los temas de democracia, participación ciudadana y derechos y obligaciones; el $11.25 \%$ no se acuerda, el $0.75 \%$ no contestaron y el $8 \%$ no fueron a la escuela.

Los resultados que aquí se presentan integran un complejo entramado de condiciones socio-económicas que explican la relación causal entre el estancamiento o recesión de la economía nacional -con su consiguiente efecto en el empleo y el ingreso de las familias- y la disposición de las y los jóvenes de participar activamente en instituciones políticas o en organizaciones de la sociedad civil que promuevan los derechos de la ciudadanía.

Asimismo, como se muestra en la Gráfica 10, a pesar del reconocimiento que las y los jóvenes encuestados tienen hacia la democracia como forma de participación de los ciudadanos en el espacio público, expresan su desconfianza a la manera en que se vive la democracia en México y, en consecuencia, la gran mayoría de ellos expresan que no estarían dispuestos a intervenir por vías institucionales (partidos políticos) en la toma de decisiones que regulan la vida política nacional.

Un dato fundamental que corrobora la pregunta de investigación que detonó este trabajo, es la correlación que las y los jóvenes establecen entre un clima de crisis económica y su voluntad de participar en actividades políticas que consoliden la vida democrática de México, tal y como muestran los resultados expresados en la Gráfica 11.

El desencanto que producen los escándalos de corrupción en México; la desigualdad social; la pobreza; la inseguridad y la violencia, ayudan a explicar esta actitud juvenil y generan inmovilidad política y desafección por la democracia como forma de vida en el espacio público nacional y regional. En este orden de ideas, se puede coincidir con lo señalado por Córdova (2018):

El problema es que la desesperanza es amiga de la inmovilidad, y es ahí, justamente, donde aquello que no nos gusta -la corrupción, la desigualdad, la pobreza, la violencia- puede florecer con mayor fuerza (Córdova, 2018, p. 8).

\section{CONCLUSIONES}

El estudio encontró una tendencia marca por los jóvenes que piensan que la política es complicada con el $48.25 \%$. Esta forma de pensar se suma otra predisposición de pensamiento con un $66.75 \%$ de los jóvenes encuestados, afirman que los problemas de la sociedad deben ser resueltos por el gobierno. Esto significa que no se ven inmersos en la vida política para afrontar con el gobierno el cambio social.

Vivat Academia. Revista de Comunicación. 15 septiembre / 15 diciembre 2020, nº 152, 69-90 


\section{Estrada Rodríguez, J. L. y Pérez Pérez, K. \\ La juventud mexicana frente a una nueva tendencia recesiva de la democracia}

Sobre el tema de democracia y participación ciudadana el estudio arrojó que el $88.50 \%$ de los encuestados no participan como militante en algún partido político, la apatía y el desinterés predomina en los jóvenes poblanos. Entre las respuestas del por qué no participar en los partidos políticos el 35.25\% afirma no tener el tiempo, el $26.78 \%$ no le interesa y el $34.70 \%$ no confía en los partidos políticos.

El cambio generacional en el sistema democrático en México está obligando a que se den procesos de mayor incorporación de los jóvenes a la vida democrática del país, fortaleciendo la transparencia en las instituciones democráticas para incentivar la credibilidad de la población joven que generacionalmente tiene mayor escolaridad y su capacidad de crítica a las propuestas electorales es cada vez mayor. (Horbath, J. Gracia, M. 2013).

Cabe mencionar que del $100 \%$ de los encuestados solo el $8.5 \%$ milita en un partido político.

Para el $30.50 \%$ de los encuestados el concepto de democracia está claro y dentro de los conceptos generales de la definición. Pero aun este porcentaje es reducido al compararlos con el $69.50 \%$ de la muestra.

Dando respuesta a la premisa principal de este estudio que es cuando la actividad económica retrocede y genera en la sociedad no solo una percepción de estancamiento económico sino democrático por la abstinencia de los grupos sociales a participar en la vida democrática de su país. Este estudio arrogó los siguientes resultados: El 58.25\% piensan que cuando hay problemas en la economía de México pierden el interés en la política. No obstante, un $16.25 \%$ afirman que siempre participan en los procesos políticos aun cuando la política en México no esté dando resultados positivos para mejorar su calidad de vida. $23.25 \%$ no les interesa participar en la política mexicana y el $2.25 \%$ no contestaron.

No es de extrañar que la participación de los jóvenes se limite cuando la economía mexicana pase por momentos de estancamiento o no crecimiento aunado a esto el tema del desempleo y la falta de oportunidades que cambien para mejorar su estado de vida son otros factores que se suman para que los jóvenes perciban con mayor fuerza esta abstinencia política. Un grupo considerado dentro de los encuestados no les interesa participar en la política mexicana, sumado a los $58.25 \%$ aumenta en un $81.5 \%$ los que de alguna manera perciben de manera negativa de los resultados de los gobiernos en turno con relación a la economía, empleo y calidad de vida.

Los jóvenes han intentado participar activamente en diferentes espacios del ámbito político y público, sin embargo, las condiciones sociales, culturales, políticas o de corrupción o discriminación generan un desencanto.

Mismo desencanto que menciona en el estudio de Martínez, J. (2013) “los jóvenes viven un desencanto con la democracia como régimen de gobierno y con la actuación de los gobernantes en México, que ha llevado a los jóvenes a admitir una visión frustrante tanto del futuro político de la nación, como de su propio porvenir".

Vivat Academia. Revista de Comunicación. 15 septiembre / 15 diciembre 2020, n 152, 69-90 


\section{Estrada Rodríguez, J. L. y Pérez Pérez, K. \\ La juventud mexicana frente a una nueva tendencia recesiva de la democracia}

La percepción de la calidad de vida y su relación con la política mexicana para los jóvenes es un tema delicado de abordar, este estudio arrojó que el 23.75\% de los encuestados afirman que la política contribuye a mejorar su calidad de vida. $28 \%$ respondieron que en parte contribuye. $33.50 \%$ piensan que no contribuye la política de México a su calidad de vida. El 13.25\% no lo sabe y el 1.5\% no contesto.

La participación ciudadana es fundamental para el ejercicio de la democracia, este estudio arrojó que solo el 19\% de los encuestados están dispuestos a participar en actividades políticas en México. En comparación con el $45.25 \%$ de los encuestados no están dispuestos a participar en actividades políticas y un $35 \%$ no lo sabe si participará. Este escenario no es favorable en términos de vivir en una sociedad democrática.

En cuanto a la educación como piedra angular de la vida en sociedad y ejercicio favorable para una sociedad democrática, el estudio dio como resultado que el $50.75 \%$ no recibieron materias dentro del sistema educativo que abordaran los temas de democracia, participación ciudadana y derechos y obligaciones de estos y un $8 \%$ no asistió a la escuela.

Se les ha exigido mayor participación e involucramiento en el mundo político y social, pero poco se les ha enseñado cómo participar. Viven un mundo donde a cada momento se les recuerda que sus vidas son producto de la democracia, que su participación es resultado de ella y que su interés refuerza y consolida la experiencia democrática, pero poco se les toma en cuenta, poco se les explica y se les informa acerca de las posibilidades de cambio, poco se les permite la expresión, ya no solo en el mundo de la política formal, sino tan solo en el mundo de la cotidianidad, ahí donde la democracia toma sentido. (Cuna, E. 2012)

El escenario no es favorable para el ejercicio de la democracia y mucho menos para una ciudadanía participante al menos en los jóvenes poblanos que muestra una opinión negativa de su gobierno, cuando se tocan temas de calidad de vida, crecimiento económico y educación política. Aunado a esto el poco interés mostrado por militar o participar en los ejercicios democráticos pinta un escenario negativo.

\section{REFERENCIAS}

Cuna, E. (2012). Apoyo a la democracia en jóvenes estudiantes de la ciudad de México. Estudio sobre el desencanto ciudadano juvenil con las instituciones de la democracia mexicana. Revista POLIS, vol. 8, núm. 2, pp. 107-151 Recuperado de http://www.scielo.org.mx/pdf/polis/v8n2/v8n2a5.pdf

García, S. \& Lukes, S. (comps.) 1999. Ciudadanía: justicia social, identidad y participación, Madrid, Siglo XXI.

Vivat Academia. Revista de Comunicación. 15 septiembre / 15 diciembre 2020, n 152, 69-90 
Horbath, J. Gracia, M. (2013) La Participación Ciudadana de los Jóvenes Mexicanos en la Construcción Social y Democrática del País al Inicio del Siglo XXI. Revista de Relaciones Internacionales, Estrategia y Seguridad. rev.relac.int.estrateg.segur. 8 (1):137-160,2013 https://www.redalyc.org/html/927/92729194007/

Instituto Nacional de Estadística y Geografía. (2015). Población. Recuperado de https://www.inegi.org.mx/temas/estructura/

Latinobarómetro Opinión Pública Latinoamericana. (2018). Directora Lagos. M. Recuperado de http://www.latinobarometro.org/lat.jsp

Martínez, J. (2013). Juventud y política: fortalecimiento de una democracia incluyente. Revista espacios públicos, núm. 38, septiembre-diciembre, pp. 9-21. Recuperado de https://www.redalyc.org/pdf/676/67629717002.pdf

O’Donnell, G., Lazetta, O. y Vargas, J. (2003) Democracia, desarrollo humano y ciudadanía, Argentina, Politeia.

Pérez, K., Mendieta, A. y Coutiño, F. (2018). América Latina: Ciudadanía, Democracia y Comunicación Política. Hernández, M. (compiladora) El Realismo Mágico de la Comunicación Política. Buenos Aires, Argentina. Ed. EPYCA EDITORIAL. ISBN: 978-987-42-6816-7

Primera Encuesta Nacional de Opinión Ciudadana. (Marzo, 2017) México: Política, Sociedad y Cambio. Grupo de Economistas y Asociados GEA e Indagaciones y Soluciones Avanzadas, S.C. ISA. Recuperado de http:// www.isa.org.mx/contenido/GIMX1703p.pdf

Sanguinetty, J. (s.f) Interacción entre Democracia y Economía. Recuperado de http://www.democraciaparticipativa.net/documentos/democr_econom.pdf

Torres, R. (2001, 24-25 septiembre). Participación Ciudadana y Educación. Una mirada amplia y 20 experiencias en América Latina [ponencia]. Segunda Reunión de Ministros de Educación del Consejo Interamericano para el Desarrollo Integral -CIDI Punta del Este, Uruguay. http://edu.jalisco.gob.mx/cepse/sites/edu.jalisco.gob.mx.cepse/files/participaci onciudadana.pdf

Yamane, T. (1967). Statistics: an introductory analysis, New York: Harper and Row, USA.

\section{AUTORES:}

\section{José Luis Estrada Rodríguez}


Profesor Investigador de la Facultad de Ciencias de la Comunicación, de la Benemérita Universidad Autónoma de Puebla. Es Doctor en Ciencias Sociales por la Universidad Autónoma del Estado de México, miembro del Sistema Nacional de Investigadores, nivel 1. Secretario Ejecutivo de la Asociación Mexicana de Ciencias Políticas (AMECIP), Miembro del Cuerpo Académico Consolidado "Comunicación Política". Autor del libro: Democracia y Campañas Electorales en América Latina, publicado en 2019 por la Universidad Do Pará, Brasil.

jluis.estrada@correo.buap.mx

Orcid ID: http:// orcid.org/0000-0003-0088-2157

\section{Ketzalcóatl Pérez Pérez}

Profesor Investigador Tiempo Completo de la Facultad de Ciencias de la Comunicación de la Benemérita Universidad Autónoma de Puebla. Doctorando en Educación Permanente por Centro Internacional de Prospectiva y Altos Estudios S.C. Maestro en Mercadotecnia por la Universidad del Valle de Puebla, UVP, Licenciado en Ciencias de la Comunicación por la Universidad Autónoma del Estado de Puebla, UPAEP, miembro de la Asociación de Comunicación Política (ACOP), miembro de la Asociación Latinoamericana Ciencia Política (ALACIP), miembro de la Asociación Mexicana de Ciencias Políticas (AMECIP) miembro de la Red Internacional de Investigadores en Marketing (RIIM), Colaborador del Cuerpo Académico de Comunicación Política adscrito a la Facultad de Ciencias de la Comunicación BUAP ketzalcoatl.perez@correo.buap.mx

Orcid ID: http:/ / orcid.org/0000-0002-5534-7234 